\title{
Effect of clover root weevil larvae on four annual forage legumes
}

\author{
J.R. CRUSH, L. OUYANG, P.J. GERARD and S. RASMUSSEN ${ }^{1}$ \\ AgResearch Ruakura, PB 3123, Hamilton \\ ${ }^{1}$ AgResearch Grasslands, PB 11008, Palmerston North \\ jim.crush@agresearch.co.nz
}

\begin{abstract}
The effect of clover root weevil (Sitona lepidus) (CRW) larval feeding on subterranean, suckling, striated and clustered clovers was compared with white clover in a glasshouse experiment. Growth of suckling, striated, and clustered clover was significantly reduced by CRW, approaching the levels of damage recorded in white clover. $\mathrm{N}$ fixation in suckling and clustered clovers was also reduced. Growth and nitrogen fixation of two subterranean clovers (cv. Denmark, cv. Leura) were changed relatively little by CRW larval feeding. The relatively high level of the isoflavonoid biochaninA that was present in subterranean clover roots may explain the species' tolerance of CRW. These results suggest that CRW may not pose a major threat to dryland farming systems based on subterranean clover.
\end{abstract}

Keywords: annual clover, clover root weevil, roots, Trifolium dubium, Trifolium glomeratum, Trifolium striatum, Trifolium subterraneum

\section{Introduction}

In New Zealand pastures, annual clovers are important where regular moisture deficits limit persistence of white clover. These areas are typically on shallow, stony lowland soils, dry north-facing hills and the inland South Island arid soils (Boswell et al. 2003). Subterranean clover (Trifolium subterraneum), suckling clover ( $T$. dubium), clustered clover (T. glomeratum) and striated clover (T. striatum) are the four most important annual clovers for sheep/beef farming in these drier areas.

Comparatively little is known about the interaction of clover root weevil (CRW, Sitona lepidus Gyllenhal (Coleoptera: Curculionidae)) with annual legumes. Hardwick (1998) reported that adult CRW showed no feeding preference among seedlings of 13 perennial or annual pasture legumes, including suckling and subterranean clovers, tested at the cotyledon stage. Mature leaves of suckling clover were not eaten if the CRW adults had a choice of other legumes, and eaten very little in a no-choice situation. Mature leaves of subterranean clover ranked well below white clover for acceptability in both choice and no-choice trials. Newly hatched CRW larvae recognised white clover roots and preferentially moved towards them when given a choice of white clover and subterranean clover roots (Johnson et al. 2004).

Isoflavonoids in red clover have been implicated in this species' relative resistance to CRW compared with white clover (Gerard et al. 2003, 2005; Crush et al. 2006; Murray et al. 2007). Subterranean clovers can contain isoflavonoids that are active in resistance of some cultivars to red legged earth mite (Wang et al. 1998). Suckling clover has a very high isoflavonoid content (Rijke et al. 2004) as well as condensed tannins (Sarkar et al. 1976; Fay \& Dale 1993) which may explain the very low levels of adult CRW feeding on this clover reported by Hardwick (1998). No information about the isoflavonoid content of clustered or striated clover has been located. Striated clover was reported to be the least preferred of 10 clover species tested for feeding preferences of adult clover head weevil (Hypera meles) by Smith et al. (1975). In this trial, significantly less feeding occurred on striated clover than on red or white clover, but striated and subterranean clover did not differ significantly.

We examined the effects of CRW larval feeding on growth and nitrogen fixation of subterranean, clustered, striated, and suckling clover. Root morphological and plant biochemical characteristics that could be important in CRW - plant interactions were also recorded.

\section{Materials and Methods \\ Plant material}

Seed of Denmark and Leura subterranean clover, suckling, striated and clustered clover and a white clover control (Kopu II), were germinated and inoculated with commercial Rhizobium inoculants. Two weeks after germination, 40 well-nodulated seedlings of each clover were transplanted into individual $15 \mathrm{~cm}$ pots of washed sand. The pots received $100 \mathrm{ml}$ of minus-N nutrient solution (Hewitt 1966) at pH 6.2-6.5, three times a week with water on intervening days. The experiment was conducted in a controlled temperature glasshouse (day $21^{\circ} \mathrm{C}$, night $12^{\circ} \mathrm{C}$ ) commencing in mid-February.

\section{Experimental design and measurements}

The design was a $6 \times 2 \times 2$ factorial (six clover species, CRW feeding or control, and two harvest times) in a randomised block design with 10 replicates per treatment. Three weeks after the clovers were transplanted, $20 \mathrm{CRW}$ eggs were placed close to the primary seedling root, one $\mathrm{cm}$ below the sand surface. Egg viability was checked on spare eggs kept on damp filter paper in a shaded Petri 
dish in the glasshouse.

Plants were harvested after 19 or $42 \mathrm{~d}$ exposure to CRW when $35 \%$ and $55 \%$ respectively of the monitored CRW eggs had hatched. The plants were washed out of the sand in buckets of water and the plant shoots were oven dried at $80^{\circ} \mathrm{C}$ for $15 \mathrm{~h}$ and weighed. Root systems were preserved in $70 \%$ ethanol and nodules and roots from plants in the CRW treatments were checked for evidence of CRW feeding. Root morphology measurements were carried out on control plants from the second harvest. Root samples were collected by cutting across the roots, $50 \mathrm{~mm}$ and $60 \mathrm{~mm}$ from the shoot base. Any nodules in the sample were removed so that they were not recorded as short, thick roots. Images of the root samples were taken using a flat-bed scanner, and root length, surface area, and diameter were measured using the WinRhizo $4.0 \mathrm{~b}^{\mathrm{TM}}$ image analysis program. After the image analysis, the preserved roots were rinsed in water and then oven-dried and weighed. Because the plants had no external $\mathrm{N}$ supply, total $\mathrm{N}$ fixed was calculated from the product of plant total dry weight (DW) and plant percent $\mathrm{N}$ for plants from the second harvest.

\section{Isoflavonoid profiles}

At the second harvest, five replicates from the annual clover control treatments were separated into shoots and roots, frozen immediately in liquid nitrogen, freeze dried, weighed, and milled using a UDY Cyclone Sample Mill (UDY Corporation, Fort Collins, CO, USA). Sub samples of $50 \mathrm{mg}$ were extracted and analysed by HPLC following methods described in Rasmussen and Dixon (1999) and adapted to isoflavonoid analysis in clovers (Crush et al. 2006). Compounds were quantified based on calibrations with known standards.

\section{Statistical analysis}

Statistical analyses were performed with MINITAB software using the General Linear Model for ANOVA (MINITAB $^{\circledR}$ 2004, version 14-2. Minitab Inc., USA). The least significant differences (LSD) were calculated at the 0.05 probability level.

\section{Results}

In the CRW treatments there were signs of larval feeding on nodules of all the clovers, particularly for those nodules that were close to where the CRW eggs had been introduced. Despite this damage, all the clovers had large numbers of intact nodules, especially on distal parts of the root system.

At both harvests, CRW feeding reduced shoot and root DW significantly $(\mathrm{P}<0.01)$ (Table 1$)$. There were significant clover type by CRW interactions affecting shoot DW $(\mathrm{P}<0.01)$ and root DW $(\mathrm{P}<0.05)$. These interactions arose from the wide variation among the clovers in their response to CRW feeding. Shoot and root DW of Denmark subterranean clover were reduced $11.5 \%$ and $7.5 \%$ respectively by CRW feeding. Corresponding values for the other clovers were: Leura subterranean clover $13.8 \%$ and $9.8 \%$; suckling clover $40.4 \%$ and $38.6 \%$; clustered clover $56.4 \%$ and $44.1 \%$; striated clover $51.2 \%$ and $35.8 \%$; white clover $59.9 \%$ and $48.4 \%$.

Whole-plant $\mathrm{N}$ concentrations varied among the clovers but were only significantly lower in the plus weevil treatments for clustered clover and suckling clover (Table 2). Total $\mathrm{N}$ fixation was reduced significantly by CRW in clustered clover, suckling clover and white clover (Table 2).

Roots of suckling, clustered, and striated clover were thinner with greater specific root lengths ( $\mathrm{cm}$ length/ $\mathrm{mg}$ root DM) than the subterranean or white clovers (Table 3 ). Total root length was greater in clustered and Denmark subterranean clover, than in white clover. Leura subterranean clover and striated clover had the shortest root systems.

Roots and shoots of both the subterranean clover cultivars had higher concentrations of genistein than the other annual clovers, with the shoots having particularly high concentrations (Table 4). BiochaninA was also significantly elevated in the subterranean clovers, but concentrations were similar in roots and shoots. Formononetin levels were higher in the subterranean clovers and striated clover than in the other species, and higher in root samples than in shoot samples. No isoflavonoids were detected in the shoots of suckling clover, but all three isoflavonoids were present at low levels in the roots.

\section{Discussion}

It had been anticipated that nodule damage caused by CRW larvae would be more serious for growth of annual clovers, than for white clover which has considerable capacity to grow new nodules to replace those damaged by CRW (Crush et al. 2005). However all the clovers had sufficient undamaged nodules to be able to make growth in a situation where they were entirely dependant on $\mathrm{N}$ fixation for nitrogen. The relatively fine and extensive root systems on the annual clovers may also be an adaptive advantage in tolerating root herbivory compared with the coarser roots of white clover.

Nitrogen fixation and growth of the subterranean clover cultivars were reduced much less by CRW larval feeding than they were on suckling, striated, clustered, or white clover. Isoflavonoids have been implicated in the resistance of some subterranean clovers to other insect pests (Wang et al. 1998). The roots of the subterranean clover cultivars were higher in biochaninA than those of 
Table 1 Effects of CRW larval feeding on shoot and root dry weight ( $\mathrm{g} / \mathrm{plant}$ ) of five annual clovers and white clover, measured after $19 \mathrm{~d}$ (Harvest 1) and $42 \mathrm{~d}$ (Harvest 2) exposure to CRW. Values are means \pm standard error of the mean.

\begin{tabular}{|c|c|c|c|c|c|}
\hline \multirow[b]{2}{*}{ Clover } & \multirow{2}{*}{$\begin{array}{l}\text { Exposure to } \\
\text { CRW (d) }\end{array}$} & \multicolumn{2}{|c|}{ Shoot DW } & \multicolumn{2}{|c|}{ Root DW } \\
\hline & & - CRW & $+\mathrm{CRW}$ & - CRW & $+\mathrm{CRW}$ \\
\hline Subterranean & 19 & $0.509 \pm 0.065$ & $0.493 \pm 0.067$ & $0.194 \pm 0.020$ & $0.185 \pm 0.026$ \\
\hline (Denmark) & 42 & $2.067 \pm 0.470$ & $1.787 \pm 0.454$ & $0.480 \pm 0.095$ & $0.414 \pm 0.105$ \\
\hline Subterranean & 19 & $0.282 \pm 0.047$ & $0.236 \pm 0.024$ & $0.117 \pm 0.014$ & $0.111 \pm 0.008$ \\
\hline (Leura) & 42 & $0.676 \pm 0.086$ & $0.590 \pm 0.097$ & $0.265 \pm 0.028$ & $0.224 \pm 0.032$ \\
\hline \multirow[t]{2}{*}{ Suckling } & 19 & $0.138 \pm 0.027$ & $0.089 \pm 0.009$ & $0.066 \pm 0.009$ & $0.053 \pm 0.003$ \\
\hline & 42 & $1.654 \pm 0.167$ & $0.723 \pm 0.131$ & $0.445 \pm 0.050$ & $0.253 \pm 0.037$ \\
\hline \multirow[t]{2}{*}{ Clustered } & 19 & $0.220 \pm 0.029$ & $0.167 \pm 0.017$ & $0.092 \pm 0.010$ & $0.072 \pm 0.009$ \\
\hline & 42 & $1.281 \pm 0.145$ & $0.488 \pm 0.068$ & $0.420 \pm 0.042$ & $0.205 \pm 0.030$ \\
\hline \multirow[t]{2}{*}{ Striated } & 19 & $0.108 \pm 0.012$ & $0.102 \pm 0.012$ & $0.044 \pm 0.003$ & $0.042 \pm 0.005$ \\
\hline & 42 & $0.433 \pm 0.041$ & $0.221 \pm 0.039$ & $0.158 \pm 0.007$ & $0.078 \pm 0.013$ \\
\hline White clover & 19 & $0.277 \pm 0.065$ & $0.161 \pm 0.034$ & $0.100 \pm 0.014$ & $0.068 \pm 0.010$ \\
\hline (Kopu II) & 42 & $3.040 \pm 0.579$ & $1.167 \pm 0.149$ & $0.675 \pm 0.147$ & $0.325 \pm 0.038$ \\
\hline
\end{tabular}

Table 2 Effects of CRW larval feeding on plant $\mathrm{N}$ concentrations (\% $\mathrm{N}$ in dry matter) and total $\mathrm{N}$ fixation (mg $\mathrm{N} /$ plant), for five annual clovers and white clover, measured after $42 \mathrm{~d}$ exposure to CRW.

\begin{tabular}{|c|c|c|c|c|c|}
\hline \multirow{2}{*}{ Clover } & \multicolumn{2}{|c|}{$\% \mathrm{~N}$} & & \multirow{2}{*}{$\mathrm{N}$ fixation } & \multirow{2}{*}{$+\mathrm{CRW}$} \\
\hline & $-\mathrm{CRW}$ & $+\mathrm{CRW}$ & $-\mathrm{CRW}$ & & \\
\hline Subterranean (Denmark) & 3.27 & 3.02 & 126.6 & & 99.2 \\
\hline Subterranean (Leura) & 2.44 & 2.31 & 25.5 & & 26.1 \\
\hline Suckling & 4.06 & 3.62 & 85.5 & & 53.0 \\
\hline Clustered & 3.38 & 2.36 & 63.5 & & 20.2 \\
\hline Striated & 3.11 & 3.18 & 22.1 & & 13.3 \\
\hline White (Kopu II) & 3.31 & 3.30 & 163.8 & & 63.6 \\
\hline $\begin{array}{l}\operatorname{LSD}_{0.05} \text { (Species) } \\
\operatorname{LSD}_{0.05}(+/- \text { CRW })\end{array}$ & 0.14 & 0.13 & 13.3 & 32.0 & 13.1 \\
\hline
\end{tabular}

Table 3 Root average diameter ( $\mathrm{mm}$ ), specific root length (SRL, cm/mg DM), and total root system length (m), for five annual clovers and white clover. Measurements were made at the second harvest on $78 \mathrm{~d}$ old plants grown without CRW.

\begin{tabular}{lcrr}
\hline Clover & Diameter $(\mathrm{mm})$ & SRL $(\mathrm{cm} / \mathrm{mg})$ & Length $(\mathrm{m})$ \\
\hline Subterranean (Denmark) & 0.317 & 35.4 & 231 \\
Subterranean (Leura) & 0.301 & 31.9 & 82 \\
Suckling & 0.241 & 48.9 & 186 \\
Clustered & 0.231 & 64.9 & 259 \\
Striated & 0.254 & 43.9 & 68 \\
White (Kopu II) & 0.318 & 26.1 & 133 \\
\hline SSD $_{0.05}$ & 0.032 & 6.8 & 73 \\
\hline
\end{tabular}

Table 4 Isoflavonoid concentration (mg/g dry weight) for five annual clovers. Measurements were made at the second harvest on $78 \mathrm{~d}$ old plants grown without CRW. nd $=$ not detectable.

\begin{tabular}{lcccccc}
\hline Clover & \multicolumn{2}{c}{ Genistein } & \multicolumn{2}{c}{ BiochaninA } & \multicolumn{2}{c}{ Formononetin } \\
& Shoot & Root & Shoot & Root & Shoot & Root \\
\hline Subterranean (Denmark) & 14.28 & 0.83 & 4.98 & 4.47 & 0.60 & 1.45 \\
Subterranean (Leura) & 13.96 & 1.07 & 4.74 & 5.55 & 0.52 & 1.44 \\
Striated & 1.01 & 0.20 & 0.21 & 0.30 & 0.73 & 1.31 \\
Clustered & 0.74 & 0.08 & 0.28 & 0.11 & 0.37 & 0.54 \\
Suckling & nd & 0.05 & nd & 0.14 & nd & 0.17 \\
\hline LSD $_{0.05}$ & 1.46 & 0.21 & 1.07 & 0.76 & 0.12 & 0.24 \\
\hline
\end{tabular}


the other clovers. BiochaninA acted as an antifeedant compound towards red legged earth mites (Ridsill-Smith et al. 1998), and reduced feeding and fecundity of subterranean termites (Boue \& Raina 2003). In red clover leaves, BiochaninA levels rise in response to CRW adult feeding (Crush et al. 2006) suggesting that this compound may be effective against CRW. BiochaninA is only mildly oestrogenic in laboratory assays so it may be a better option as a natural insect pest resistance factor for pasture legumes than compounds such as formononetin that can compromise ewe fertility (Kelly et al. 1980). Formononetin concentrations were higher in roots than shoots of the subterranean clovers and this is a useful model for distribution of isoflavonoids in grazed clovers. The formononetin concentrations in the subterranean clovers were lower than those active in deterring CRW in red clover (Gerard et al. 2005) which suggests that biochaninA may be a more important antifeedant compound for CRW in subterranean clover. We cannot exclude the possibility that combinations of isoflavonoids may be more effective against CRW, than the concentration of any one compound.

From published descriptions of the isoflavonoid and tannin profile of suckling clover (Rijke et al. 2004; Sarkar et al. 1976; Fay \& Dale 1993), as well as its nonacceptance in CRW adult feeding trials (Hardwick 1998), we expected this clover to be resistant to CRW. However this was not the case in our experiment. It is possible that there are differences in bioactive chemical profiles between different lines of suckling clover, as has been shown for red and subterranean clovers.

The no-choice experimental design used in this experiment probably resulted in higher levels of CRW damage than would occur in a mixed sward. In pasture, CRW adult feeding damage on non-preferred legumes is usually restricted to "test bites" (Eerens et al. 2001), and presumably less egg-laying, and lower larval densities around the roots. Our results suggest that some of the annual clovers that are important to farming on drier soils will not be seriously damaged by CRW. Subterranean clover in particular has a high degree of tolerance to CRW. The biology of annual clovers will also contribute to their persistence in dryland country. If there are no or few perennial clovers present and summer conditions are dry, CRW larval populations will not be maintained and will have to be re-established seasonally by ingress of adults from moister areas. CRW adults only fly during summer, well before germination of the annual clovers. Therefore CRW populations may not reach such critical levels that performance of striated, suckling, and clustered clover is seriously compromised. The results suggest that farm systems based on annual clovers will maintain productivity in spite of CRW, although this conclusion requires field testing.

\section{ACKNOWLEDGEMENTS}

This work was funded by FRST Contract C02X0406.

\section{REFERENCES}

Boswell, C.C.; Lucas, R.J.; Lonati, M.; Fletcher, A.; Moot, D.J. 2003. The ecology of four annual clovers adventive in New Zealand grasslands. Legumes for dryland pastures. Grassland Research and Practice Series 11: 175-184.

Boue, S.E.; Raina A.K. 2003. Effects of plant flavonoids on fecundity, survival and feeding of the Formosan subterranean termite. Journal of Chemical Ecology 29: 2575-2584.

Crush, J.R; Cooper, B.M.; Woodfield, D.R.; Gerard, P.J. 2005. Development of clovers that are tolerant to clover root weevil. Proceedings of the New Zealand Grassland Association 67: 23-27.

Crush, J.R.; Gerard, P.J.; Rasmussen, S. 2006. Formononetin in clovers as a feeding deterrent against clover root weevil. Advances in pasture plant breeding. Grassland Research and Practice Series 12: 135-139.

Eerens, J.P.J.; Cooper, B.M.; Willoughby, B.E.; Woodfield, D.R. 2001. Searching for clover root weevil (Sitona lepidus) resistance/tolerance - A progress report. Proceedings of the New Zealand Grassland Association 63: 177-181.

Fay, M.F.; Dale, P.J. 1993. Condensed tannins in Trifolium species and their significance for taxonomy and plant breeding. Genetic Resources and Crop Evolution 40: 7-13.

Gerard, P.J.; Crush, J.R. 2003: Feeding habituation to red clover by clover root weevil adults. New Zealand Plant Protection 56: 129-132.

Gerard, P.J.; Crush, J.R.; Hackell, D.L. 2005. Interaction between clover root weevil and red clover lines selected for formononetin content. Annals of Applied Biology 147: 173-181.

Hardwick, S. 1998. Laboratory investigations into feeding preferences of adult Sitona lepidus Gyllenhal. pp. 5-8. In: Proceedings 51st New Zealand Plant Protection Conference.

Hewitt, E.J. 1966. Sand and water culture methods used in the study of plant nutrition. pp 431-432 In: Technical Communication No 22. Commonwealth Bureau of Horticulture and Plantation Crops.

Johnson, S.N.; Gregory, P.J.; Murray, P.J.; Zhang, X.; Young, I.M. 2004. Host plant recognition by the root feeding clover weevil, Sitona lepidus (Coleoptera: Curculionidae). Bulletin of Entomological Research 94: 433-439.

Kelly, R.W., Shackell G.M., Allison A.J. 1980. Reproductive performance of ewes grazing red clover (Grasslands Pawera) or white clover-grass pasture at 
mating. New Zealand Journal of Experimental Agriculture 8: 87-91.

Murray, P.J.; Cheung, A.K.M.; Abberton, M.T. 2007. Intraspecific variation in Trifolium pratense: impact on feeding and host location by Sitona lepidus (Coleoptera, Curculionidae). Journal of Pest Science 80: 51-57.

Rasmussen, S.; Dixon, R.A. 1999. Transgene-mediated and elicitor-induced perturbation of metabolic channelling at the entry point into the phenylpropanoid pathway. Plant Cell 11: 1537-1551.

Rijke, E.; Zappey, H.; Ariese, F.; Gooijer, C.; Brinkman, U.A.T. 2004. Flavonoids in Leguminosae: analysis of extracts of $T$. pratense L., T. dubium L., T. repens L., and L. corniculatus L. leaves using liquid chromatography with UV, mass spectrometric and fluorescence detection. Analytical and Bioanalytical
Chemistry 378: 995-1006.

Ridsdill-Smith, T.J.; Jianf, Y.; Ghisalberti E.L. 1998. A method of test compounds for feeding deterrence towards redlegged earth mite (Ascarine: Penthaleidae). Annals of Applied Biology 126: 593-600.

Sarkar, S.K.; Howarth, R.E.; Goplan, B.P. 1976. Condensed tannins in herbaceous legumes. Crop Science 16: 543-546.

Smith, C.M.; Knight, W.E.; Pitre, H.N. 1975. Feeding preference of the clover head weevil on clovers of the genus Trifolium. Journal of Economic Entomology 68: 165-166.

Wang, S.F.; Ridsdill-Smith, T.J.; Ghisalberti, E.L. 1998. Role of isoflavonoids in resistance of subterranean clover trifoliates to the redlegged earth mite Halotydeus destructor. Journal of Chemical Ecology 24: 20892100. 